\title{
Frontal fibrosing alopecia and ulerythema ophryogenes as two entites that can transist one into another
}

\author{
Magdalena Piotrkowicz'1, Witold Owczarek²
}

\begin{abstract}
${ }^{1}$ Department of Internal Medicine with Cardiology Unit, District Hospital in Pultusk, Pultusk, Poland ${ }^{2}$ Department of
Dermatology, Military Institute of Medicine in Warsaw, Warsaw, Poland
\end{abstract}

Corresponding author: Dr. Magdalena Piotrkowicz, E-mail: mpiotrko@gmail.com

\begin{abstract}
The authors report two clinical cases of progressive hair loss in frontoparietal area of the scalp accompanied by a total loss of eyebrows that occurred in mother and daughter. They are diagnosed with scarring alopecia which is a condition described in a wide group of diseases that cause diagnostic and classification problems. The symptoms that occurred in presented patients are characteristic for frontal fibrosing alopecia, a disease histologically similar to lichen planopilaris, typically appearing in women at postmenopausal age, and ulerythema ophryogenes, one of the keratosis follicular disorders that appears in early infancy and has familial occurrence. The authors hypothesize that these two diseases have much in common and are likely to evolve one into another.
\end{abstract}

Key words: Scarring alopecia; Frontal fibrosing alopecia; Ulerythema ophryogenes; Primary cicatrical alopecias

\section{INTRODUCTION}

There is a wide group of diseases that can result in scarring alopecia. Accoriding to clinical features they can be divided into 2 subgroups [1]. The first one is scarring follicular keratosis - a group of hereditary disorders with an early onset (usually occuring from early infancy). This group includes atrophoderma vermiculata (acne vermiculata, folliculitis ulerythematosa vermiculata), ulerythema ophryogenes (keratosis pilaris atrophicans faciei) and keratosis pilaris spinulosa decalvans. The second subgroup is lichen planopilaris consisting of entities histologically very closely related to lichen planus; namely frontal fibrosing alopecia, GrahamLittle-Piccardi-Lassueur Syndrome and fibrosing alopecia in pattern distribution.

The diseases mentioned above have been described as clinically and histologically overlapping. All of them are characterized by inflammation and destruction of the hair follicle resulting in permanent alopecia.
They are often described as one group under the name of primary cicatrical alopecias (PCA) [2]. The pathogenesis of PCA is still unknown, although there are some reliable hypotheses of immunopathological mechanisms. According to several reports, the damage of epithelial hair follicle stem, located at the bulge region of the arrector pilli muscle, seem to play an important role, as it's responsible for regenerative processes of the hair follicle and the hair cycle. The bulge region is surrounded by T-lymphocytes, Langerhans cells, macrophages and antimicrobial peptides and it is thought to be a place with immune privilege. The damage is caused by pro-inflammatory events like type-I interferonassociated cytotoxic inflammation, loss of hair follicle privilege, loss of immunosuppressive "no danger" signals. However; this concept doesn't explain other features like epidermal and sebaceous-gland atrophy, scalling, pustules, arrector pili muscle loss, which are characteristic for PCA [3].

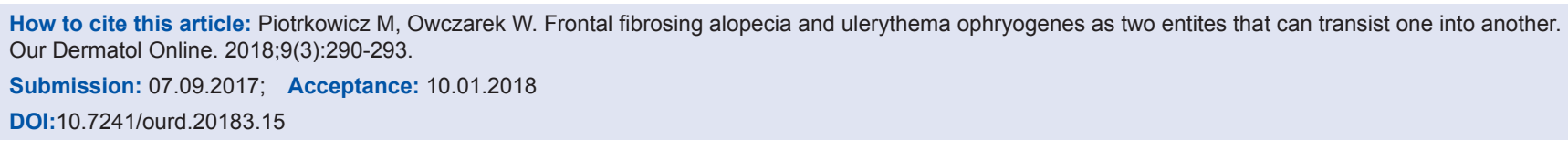


The cases reported below include inflammation of follicles and eyebrow loss, most characteristic clinical features occurring in both frontal fibrosing alopecia and ulerythema ophryogenes.

\section{CASE REPORTS}

\section{Case 1}

A 60-year-old woman presented with a loss of eyebrows and progressive loss of scalp hair (Figs. la and lb). The onset of the disease is unknown, however both patients claimed that their eyebrows have always been "weak". Case history revealed no other complaints. The scalp examination revealed follicular hyperkeratosis and scarring alopecia over frontal area of the scalp with marked recession of the frontal hairline. The complete eyebrow loss was also observed. The patient was treated with potent topical steroids (clobetasol propionate) and prescription liquid with $10 \%$ tinctura capsici and 1\% chloramphenicol. After a 3-year follow-up, in addition to former symptoms, subungual keratosis was observed. Yet again, moderate steroid (mometasone furoate) and liquid with tinctura capsici plus chloramphenicol were administered. The patient presented 4 months later; the treatment revealed good control of progressive scarring alopecia and inflammatory changes of follicles, whereas hyperkeratotic papules on the scalp were only partially treated. The treatment with tinctura capsici and chlorampfenicol was continued.

\section{Case 2}

This 36-year-old woman, the daughter of patient 1, presented with progressive loss of hair and eyebrows(Figs. lc and ld). She was diagnosed with Raynaud disease 2 years earlier. There are no other diseases in the patient's medical history. The physical examination disclosed keratosis pilaris on the skin of the upper cheek areas and the scalp, inflammation of the follicles, scarring alopecia over the frontal area of the scalp with marked recession of the frontal hairline, eyebrow hair loss. Topical steroids (mometasone furoate), adapalene, the prescription liquid mentioned above were prescribed.

\section{DISCUSSION}

Frontal fibrosing alopecia (FFA) was first described in 1994 by Kossard [4], hence its other name - the Kossard's

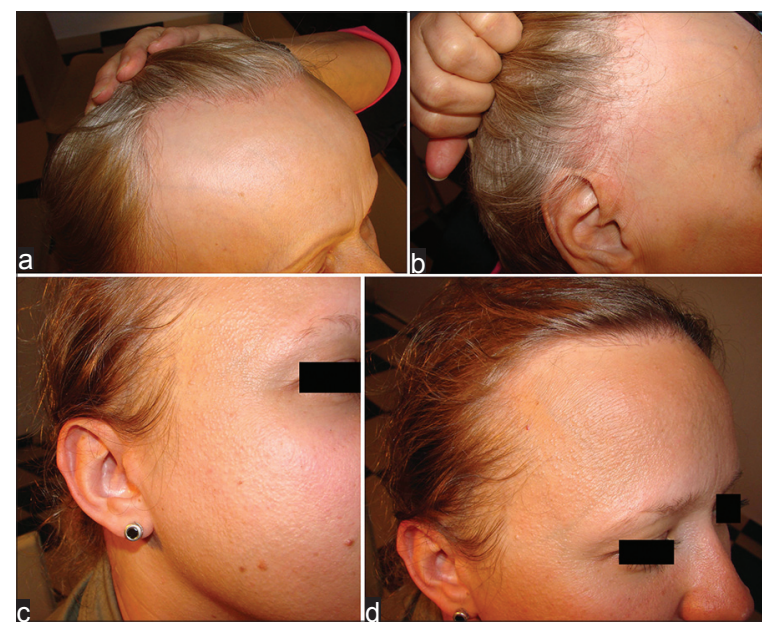

Figure 1: $a$ and $b$ Patient one. Please notice the loss of eyebrows and noticeable loss of scalp hair accompanied with cicatrical skin lesions. $c$ and d Patient two. The follicular keratosis is associated with the onset of hair and eyebrows alopecia.

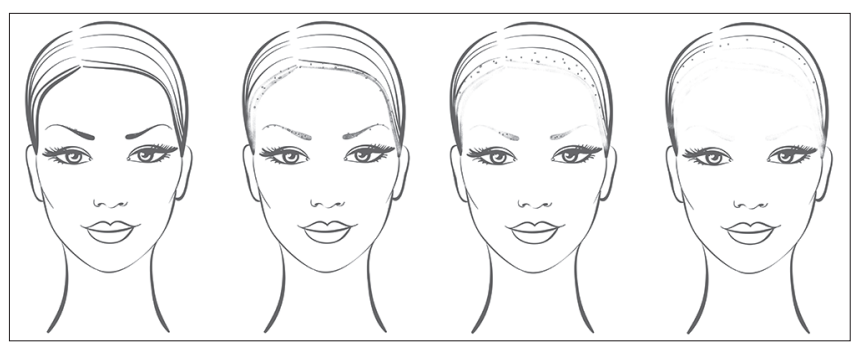

Figure 2: The hypothetical transition of UO into FFA. Areas affected by follicular keratosis marked red. Please note the disappearance of the keratosis followed by hair loss in affected areas.

disease. Clinically it is characterized by frontoparietal recession of the hairline, often accompanied by eyebrow loss. Histological features like perifollicular fibrosis and lymphotic inflammation around the follicles suggest a substantial resemblance to lichen planopilaris [5], although no skin lesions characteristic for lichen planus are seen on the skin in FFA. FFA was first described in postmenopausal women and a hormonal background was considered [4]; however, according to some recently published case reports, it may also occur in men and premenopausal women. No genetic role in pathogenesis of FFA has been proven [6]. Nevertheless, certain cases that could suggest it have been described [7-10]. The hair loss is irreversible as in all scarring alopecias. No treatment has been found to significantly reverse the progressive changes. The use of topical or systemic antibiotics, corticosteroids or, antimalarial agents has no significant effects. According to some authors, the 5-alfa-reductase inhibitors (finasteride, duatasterid) and intralesional triamcinolone have produced several positive outcomes $[10,11]$. Others have described relevant results of the application of prescription liquid 
with tinctura capsici with $1 \%$ chloramfenicolum if administered alternated with superpotent steroids. Such treatment may prevent recurrence of the disease and has also been found effective in other types of cicatricial alopecia [12]. The efficacy of treatment is difficult to prove due to potential spontaneous stabilization in some patients [4].

Ulerythema ophryogenes (UO), also known as keratosis pilaris atrophicans faciei (KPAF) or folliculitis rubra, was first described in 1878. The name derives from the Greek-"ule", which means scar and "orphys", which means "eyebrow". UO is a variant of keratosis pilaris characterized by erythematous follicular papules of the eyebrows and cheeks followed by a gradual loss of hair. Some follicles are affected by inflammatory changes that lead to their destruction as well as to alopecia and plain scars of a honeycomblike structure. The honneycomb pattern, however suggests a different cicatrical disease - atrophoderma vermiculatum [13]. According to the authors, UO typically appears in childhood and its' progression usually stops after puberty. It has been described as inherited in autosomal dominant pattern with variable penetrance although sporadic prevalence is also possible. UO is considered a rare and often misdiagnosed syndrome [14]. The frequent delay in diagnosis of the disease may be attributed to a fact that patients fail to notice it or do not consider it a problem (e.g., due to common eyebrow make up routines and depilation). In fact, it may be more common than it has been described. Treatment is similar to other variants of scarring alopecia. There is no perfect cure. The hair loss is irreversible. Steroids, antibiotics and retinoids have been administered without notable effects.

The study presents two cases of cicatricial alopecia occurring in mother and daughter that can be best described as FFA. Familiar occurrence of this disease has been described before. Nevertheless, the clinical picture of the 36 years old daughter includes follicular keratosis found in UO. Therefore authors hypothesize that these two diseases may have more in common than it was thought before.

Ulerythema ophryogenes usually appears in childhood with follicular keratosis of the eyebrows eventually leading to their irreversible alopecia. The problem is frequently ignored, especially by women who often change the shape of their eyebrows to obtain a satisfactory cosmetic effect. Many women also use the eyebrow pencil or pomade to define the shape of their eyebrows. If the clinical picture of both patients described shows the same disease, further alopecia, involving the frontal area of the scalp at this time appears two - three decades after the loss of the eyebrows. Moreover, in the area where the eyebrows were the follicular keratosis eventually disappears, but it is present on the forehead and the border of the scalp, at least until permanent alopecia. In severe cases there is no visible follicular keratosis. Authors suggest that lack of follicular keratosis in advanced UO (or FFA) can be explained by the fact that if all follicles have been destroyed by the disease process there is no longer room for follicular keratosis. Alopecic skin is atrophic and lacking skin appendices; the only area with possible visible keratosis is the border between alopecic skin and the remaining hair. The considerable time interval between eyebrow loss and scalp alopecia leads to the conclusion that ulerythema ophryogenes and frontal fibrosing alopecia are two different diagnoses, while authors suggest that these two may have some connection to each other. The hypothetical transition of UO into FFA has been proposed in figure 2 .

\section{CONSENT}

The examination of the patient was conducted according to the Declaration of Helsinki principles.

\section{REFERENCES}

1. Turegano MM, Sperling LC. Lichenoid folliculitis: A unifying concept. J Cutan Pathol. 2017 Mar 26. doi: 10.1111/cup.12938.

2. Ross EK, Tan E, Shapiro J. Update on primary cicatricial alopecias, J Am Acad Dermatol. 2005;53:1- 37.

3. Harries MJ, Meyer KC, Chaudhry IH, Griffiths CEM, Paus R. Does collapse of immune privilege in the hair-follicle bulge play a role in the pathogenesis of primary cicatricial alopecia? Clin Exp Dermatol. 2009;35:637-44.

4. Kossard S. Postmenopausal frontal fibrosing alopecia: Scarring alopecia in pattern distribution. Arch Dermatol. 1994;130:770-4.

5. Gálvez-Canseco A, Sperling L. Lichen planopilaris and frontal fibrosing alopecia cannot be differentiated by histopathology. J Cutan Pathol. 2018;45:313-31.

6. Esteban-Lucia L, Molina-Ruiz AM, Rewuena L. Actualizacion en alopecia frontal fibrosante. Actas Dermosifiliogr. 2017;108:293-304.

7. Cranwell WC, Sinclair R. Familial frontal fibrosing alopecia treated with dutasteride, minoxidil and artificial hair transplantation. Australas J Dermatol. 2017;58:e94-e96.

8. Dlova N, Goh C-L, Tosti A. Familial frontal fibrosing alopecia. Br J Dermatol. 2013;168:220-2.

9. Junqueira Ribeiro Pereira AF, Vincenzi C, Tosti A. Frontal fibrosing alopecia in two sisters. Br J Dermatol. 2010;162:1154-5.

10. Vãnó-Galván S, Molina-Ruiz AM, Serrano-Falcón C, AriasSantiago S, Rodrigues-Barata AR, Garnacho-Saucedo G, et al. Frontal fibrosing alopecia: A multicenter review of 355 patients. 


\section{www.odermatol.com}

J Am Acad Dermatol. 2014;70:670-8.

11. Donovan JC, Samrao A, Ruben BS, Price VH. Eyebrow regrowth in patients with frontal fibrosing alopecia treated with intralesional triamcinolone acetonide. Br J Dermatol. 2010;163:1142-4.

12. Wasyłyszyn T, Borowska K. Program edukacyjny: dermatologia w praktyce. Frontal Fibrosing Alopecia. Dermatol Kosmetol Prakt. 2016;2:71-4.

13. Morton CM, Bhate C, Janniger CK, Schwartz RA. Ulerythema ophryogenes: updates and insights. Cutis. 2014;93:83-7.

14. Dianzani C, Pizutti A. Ulerythema ophryogenes, a rare and often misdiagnosed syndrome: analysis of an idiopathic case. Int J
Immunopathol Pharmacol. 2011;24:523-7.

15. Dianzani C, Pizutti A. Ulerythema ophryogenes, a rare and often misdiagnosed syndrome: analysis of an idiopathic case. Int J Immunopathol Pharmacol. 2011;24:523-7.

Copyright by Magdalena Piotrkowicz, et al. This is an open-access article distributed under the terms of the Creative Commons Attribution License, which permits unrestricted use, distribution, and reproduction in any medium, provided the original author and source are credited.

Source of Support: Nil, Conflict of Interest: None declared. 